\title{
I. Eroffinung.
}

Der Vorsitzende Thoma-Heidelberg eröffnete die Beratungen am 23. April 1928 um 9 Uhr 50 Min. Er gedenkt der im letzten Jahre verstorbenen deutschen Staatsrechtslehrer Heinrich Rosin, Kąrl Rieker und Philipp Zorn. Sodann begrüßt er die neuen Mitglieder Adamowich-Prag, Fleiner-Zürich, Liermann-Freiburg i. B. und WurmbrandtGraz.

Schriftführer Nawiasky erstattet den Geschäfts- und Kassenbericht. 